\title{
A Study of College Students' Autonomic Foreign Language Learning in an E-Learning Environment at Private Colleges
}

\author{
Yanfeng $\mathrm{Zu}$ \\ Huali College, Guangdong University of Technology, Guangzhou 510000, China \\ 740724679@qq.com
}

Keywords: E-learning; private colleges; foreign language autonomic learning; language learning strategy.

\begin{abstract}
It is critical to cultivate the ordinary college students' capacity of autonomic learning in an e-learning environment. This study puts forward the strategies towards improved private college students' autonomic learning through analyzing the current situation of autonomic learning. In this paper, we come to the conclusion: raising the students' awareness of autonomic learning is a necessary prerequisite to cultivate the capacity of foreign language learning; optimizing the Internet resources is an efficient way of developing the ability of self-directed learning; actively studying the strategic guidance is the first step in improving the ability of self-directed learning of foreign languages; assessment and monitoring is also essential to ensure the improvement of autonomic learning.
\end{abstract}

\section{The Demarcation between E-Learning and the Definition of Autonomic Foreign Language Learning.}

\subsection{E-learning}

E-learning is commonly referred to intentional use of networked information and communications technology in teaching and learning. Theoretically e-Learning can be defined in this way: the utilization of electronic systems such as Internet, computers, multimedia CDs and aiming to reduce the amount of expenses and goings and comings.

\subsection{Foreign Language Autonomic Learning}

Henri Holec (1981) is the first one to apply the autonomic learning theory into foreign language education field. He elaborated the concepts, connotation and practice of autonomic learning in his treatise, Autonomy and Foreign Language Learning. He believed that autonomic learning meant the learners were taking responsibilities for their study during the whole process of learning and he also emphasized the learners' abilities such as independence, initiative and innovation.

\section{The Current Situation of Students' Autonomic Foreign Language Learning in Private Colleges}

Private colleges rely on public colleges, funded by non-governmental organization, and the tuition of private colleges is generally higher than that of public colleges. Therefore, students in private colleges mostly are from relatively superior families and commonly equipped with computers. They have diversified mainstream ideologies, follow the new trend and have a strong ability of accepting new things. In an e-learning environment, the input of languages is mounting day by day; the learning objectives are visible, audible and interpretable, as well as with interesting images affiliated. Therefore, as an emerging media, e-learning has become one of the popular ways utilized by private colleges’ students for their foreign language studies. However, it has been found that most of these students are poor in self-discipline, lacking of awareness of self-management, and weak in self-control. With too much information to drown in, the students born after 1990s have showed a strong passion. Meanwhile, there are also many problems to be solved.

\subsection{Lack of abilities in self-independence and self-discipline for learning}

Most students of 90s in private colleges are from the single-child families; their conditions in the home are richer than ordinary families'. Once they leave their families and live in a college campus, their shortages are revealed, e.g., higher depend on others, be lazy in studying, and weak in 
self-independent. When they have some problems, they usually lay their hopes on others and are unwilling to work out solutions by themselves. Most of private college students are weak in study initiative or study without appropriate schedule and plans, lacking for the ability of self-discipline and self-control. They cast only a passing glance at network resource in e-learning, and then stop after scratching the surface of the knowledge. Indeed, there is little help for them.

\subsection{Lack of skills in using Internet for self-learning}

Currently, there are many resourceful learning materials on the Internet, for instance, learning videos, e-books, course counseling and career guidance. However, students are easily disrupted by misleading information that will waste their time and energy. When searching resources, students are tired of learning when meeting some irrelevant information. Research showed that a number of students did not know how to integrate the resources with a shortage of resource management capacity.

\subsection{Lack of an effective monitoring system}

Currently, the students conduct e-learning courses on their own. They seldom set an appropriate learning goal, keep a specific learning progress, and build an effective self-monitoring system, from which lead to low study efficiency, no mention what they can attain from learning. So, teachers are supposed to lead and guide their students how to do e-learning in an appropriate way, place some teaching discussion activities into e-learning practicing. Alternately, recourses collection that needed in course learning can be finished in e-learning.

\section{The Road towards Improved Private College Students' Autonomic Learning}

\subsection{Strengthen the students' awareness of autonomic learning}

During the process of e-learning, initiative and self-disciplined leaning is critical for learners. They are in a free and random Internet world, surrounded by a complicated external learning environment. These factors will all lead to an imperfect e-learning result. So, if these undergraduate students want to achieve their expected effects in e-learning, they are bound to transfer their role and awareness, straighten mentality, set clear learning goal, build up their awareness of self-discipline, set up study plans and effective self-monitoring strategies, and launch a serious of study activities with plans step by step. Ultimately, they will form the habit of independent thinking and comprehensive ability will be improved largely. Educators are supposed to activate and strengthen learners' inner motivation by evoking their study interests and confidence. Only by this way, can students fully focus on study objectives, and concentrate on the minds thus arousing the studying enthusiasm. Teachers are supposed to provide all kinds of theories and knowledge about cognitive and strategy helping students to form an awareness and notion of autonomic study.

\subsection{Optimizing online resources}

The fundamental of e-learning is to develop online learning resource based on big data technique, which will have influence on the effects of online study. Teachers can integrate online resource into autonomic learning platforms, reaching to a resource complementarity, improving students' motivation of e-learning. The construction of online learning resource should follow the features of e-learning process, such as, enjoying, enlightening, disconnecting and compressing. Teachers are supposed to disintegrate and extract the knowledge, highly targeted, input learning content with various media, which can reduce the difficulty of study, and ensure that students persist in studying. Moreover, the time of the videos, which are mainly about short videos, short animated films and mini-games, is generally controlled within ten minutes. Some related self-test exercises should be set up at the end of each video, from which students are capable to test them timely, so as to know their study situation and adjust their study strategy.

\subsection{Cultivation of self-learning strategy.}

It's crucial for college students to get the hang of self-judgment, self-monitoring and self-control. Therefore, to cultivate students' capability of self-directed learning is of vital importance. And it's of necessity to assure the progress of effective leading while promoting the ability of self-directed learning. 


\subsubsection{Raising their awareness of self-directed learning.}

Promote their sense of belonging in the course of online learning through places beneficial to interaction and communication like We-chat, Micro blog to accomplish the goal of mutual communication among students and teachers, to analyze and settle the conundrum faced in learning so as to power the students' perception of self-directed learning online in emotional aspects. Moreover, lead them to master proper methods as well as techniques of learning and encourage them to experience communicating and sharing with others personally in class so as to strengthen their self-efficacy and behavior intention through e-learning.

3.3.2 Cultivating students' capability of obtaining, analyzing and integrating resources by means of Internet searching.

With too much miscellaneous information to drown in while searching online, it's of supreme essence to cultivate students' ability of dealing with information. Teachers are supposed to cultivate students' capability of analyzing and integrating necessary information. Only when students master the techniques of screening, collating and integrating and so on will they transform the complex and dubious information into something worthwhile and easy to understand. Teachers are also supposed to guide students to discriminate information and exchange experience online, to help them grasp the rule and techniques of learning online and to teach them how to manage resources in a better way so that they are able to take advantage of the outer environment as best as they can and create a preferable condition for self-directed learning by choosing appropriate materials, time and surroundings for learning while facing numerous resources.

\subsubsection{Making a constant attempt to guide students to make plans and objectives of study}

On students' possessing the consciousness of autonomic learning, teachers could assist them to set concrete, detailed, reasonable and feasible goals which turn out to be a well-planned learning project and make correspondent adjustments based on students' changes of learning situations. Teachers are supposed to teach them how to understand the metacognitive strategy, to activate them as much as possible, to usher them how to monitor and adjust by means of the metacognitive strategy, to churn out the most suitable methods for the learners and to guide them to achieve the goals of self-learning ultimately by a series of management of time, resources and environment.

\subsubsection{Leading students to study cooperatively}

Learn with fellow students and teachers cooperatively in a way of discovery-learning by making full use of abundant resources in the base of automatic learning via Internet, automatic experience center and communities like English Village and English Salon. Teachers can also set up learning contexts, distribute learning tasks and make compositions online through a webpage (e.g., http://www.pigai.org), then each group could analyze their actual contexts according to tasks and problems issued by teachers, including collaboration, usage, frequency and so forth and make discussions in groups so as to settle the problems of study.

\subsection{Self-assessment and monitoring}

Self-assessment and self-monitoring are for those who can assess and monitor themselves to solve the problems faced in language learning timely and adjust their learning strategies and methods in case of outcomes not up to expectations. Teachers are supposed to encourage students use the met-cognitive-strategy. Learners are supposed to monitor, control and accommodate their own perception while high-level learners are able to judge their own level objectively by selecting profitable learning procedures and methods according to the features of the subject.

\section{Conclusions}

Firstly, teachers in private colleges are supposed to usher students to precede automatic learning. Meanwhile, they are also supposed to attach useful materials to the development and construction of online learning resources, improve the quality and quantity of resources. Secondly, teachers and students in private colleges are supposed to work closely in order to create an online-learning environment and cultivate students' capacity of applying met cognitive strategy, self-monitoring and self-adjustment. Finally, it is important for students to actively use the flipped classroom, get 
feedbacks of their self-directed learning promptly. Eventually, students are able to improve their self-efficacy and enhance the capability of self-monitoring.

\section{References}

[1]. Holec H. Autonomy and Foreign Language Learning [M]. Oxford: Pergamon, 1981

[2]. SOM NAIDU, E-Learning: A Guidebook of Principles, Procedures and Practices, (C) 2nd Revised Edition, CEMCA, 2006, First published in 2003.

[3]. O’Malley, J. M \& Chamot, A. U. Learning Strategies in Second.

[4]. Neda Mohammadi, Vahid Ghorbani, Farideh Hamidi,(2011) Effects of e-learning on Language Learning, Journal, Procedia Computer Science 3 464-468.

[5]. Yunsheng Zhong, 2008,A Study of Autonomy English Learning on the Internet Foreign Language Department of Qinzhou University Qinzhou 535000,China. (In Chinese)

[6]. Winne, P. H. (2010). Improving measurements of self-regulated learning. Educational Psychologist, 45(4), 267-276. 